\title{
Article \\ Effects of Pacifiers on Peripheral Capillary Oxygen Saturation during Wake Time
}

\author{
Luca Levrini * ${ }^{\mathbb{D}}$, Francesca Riccaboni, Vittorio Maurino, Lorenzo Azzi and Luana Nosetti \\ Department of Human Sciences, Innovation and Territory, Department of Medicine and Surgery, School of \\ Dental Hygiene, University of Insubria, 21100 Varese, Italy; f.riccaboni@gmail.com (F.R.); \\ v.maurino@uninsubria.it (V.M.); l.azzi@uninsubria.it (L.A.); luana.nosetti@uninsubria.it (L.N.) \\ * Correspondence: luca.levrini@uninsubria.it; Tel.: +39-0332-299730
}

Citation: Levrini, L.; Riccaboni, F.;

Maurino, V.; Azzi, L.; Nosetti, L.

Effects of Pacifiers on Peripheral Capillary Oxygen Saturation during Wake Time. Appl. Sci. 2021, 11, 6042. https://doi.org/10.3390/app11136042

Academic Editors: Alessandra

Lucchese, Dario Bertossi and

Riccardo Nocini

Received: 8 May 2021

Accepted: 23 June 2021

Published: 29 June 2021

Publisher's Note: MDPI stays neutral with regard to jurisdictional claims in published maps and institutional affiliations.

Copyright: (c) 2021 by the authors. Licensee MDPI, Basel, Switzerland. This article is an open access article distributed under the terms and conditions of the Creative Commons Attribution (CC BY) license (https:// creativecommons.org/licenses/by/ $4.0 /)$.

\begin{abstract}
We studied the variations in peripheral capillary oxygen saturation (SpO2) during wake time in relation to pacifier use and to the following different positions: supine at $0^{\circ}$, supine at $30^{\circ}$ (in babies under one year) vs. sitting (in babies between 1 and 3 years of age). We observed 54 patients under the age of three years, weighing over $1.800 \mathrm{~g}$. Peripheral oxygen saturation was recorded for at least $40 \mathrm{~min}$ per patient in the following positions: $20 \mathrm{~min}$ lying supine at $0^{\circ}(10 \mathrm{~min}$ with a pacifier and $10 \mathrm{~min}$ without); $20 \mathrm{~min}$ lying supine at $30^{\circ}$ inclination or in a sitting position if the baby was older than one year (10 $\mathrm{min}$ with a pacifier and $10 \mathrm{~min}$ without). Pacifier use improved the peripheral oxygen saturation both in the $0^{\circ}$ supine position, and at $30^{\circ}$ in a sitting position. No significant differences were observed in the $\mathrm{SpO} 2$ levels comparing the different positions. In conclusion a pacifier thus seems to have a positive effect on respiration.
\end{abstract}

Keywords: pacifier; capillary oxygen saturation; SIDS

\section{Introduction}

The relationship between malocclusions and pacifier use is a much-debated issue. Although no definite conclusions that are consistent with the principles of evidence-based medicine have been drawn, the general consensus regards pacifier use as harmful if it does not comply with the recommended timing and modalities [1-4]

Suction is an innate reflex that appears in the prenatal stage and is one of the first muscular coordination abilities of a fetus [5]. A pacifier stimulates this reflex. Its use is described as "non-nutritive suction behavior", comparable to finger suction. Infants have a natural suction instinct that is considered to be the first feeding instinct. If this instinct is not completely satisfied by the maternal breast or feeding bottle, the baby will experience feelings of frustration. This does not happen if the baby engages in a non-nutritive suction habit [6]. It is no coincidence that, in English, this object is called a pacifier, underlining its effectiveness in soothing the baby. Pacifiers also have some benefits, as follows:

They reduce the perception of pain and the state of agitation in babies under 6 months old, whether born full term or prematurely, or enduring minor procedures in the Emergency Room [7].

In premature babies, they facilitate the development of a nutritive suction habit and improve digestion at the intestinal level, thus reducing hospitalization time [8]; they also reduce finger suction habits [9].

Pacifiers are also associated with possible risks, as they can cause dental misalignment and malocclusions if used by children older than two years [10]; hinder breastfeeding if used during the first month after birth, before breastfeeding has been consolidated [11]; and lead to the risk of otitis media, especially in children over one year of age [12].

The guidelines published in 2016 included pacifier use among the protection factors against Sudden Infant Death Syndrome (SIDS) during the first year of life [13]. Various hypotheses have been drawn on the role of a pacifier in reducing the risk of SIDS, for 
instance, preventing "rebreathing" by preventing the direct contact of the face with the sheets; lowering the threshold of awakening; and causing a greater arousal in the case of hypoxia [14].

The use of a pacifier also keeps the tongue in the anterior position, modifying the aerial spaces and keeping the airways open [15]. These positive effects seem to be unaffected by the possible loss of the pacifier during sleep. One study [16] showed that pacifier use in preterm infants is associated with a small, but significant and persistent forward movement of the jaw, which enables the upper airways to expand. This theory was confirmed by another study [17] that showed that a pacifier facilitates an adequate airflow, and therefore an adequate peripheral oxygen saturation, through the oral cavity in the case of nasal airway obstruction.

In a previous paper, we demonstrated that pacifier use is correlated with a statistically significant reduction in the number of pathological apneas/night (AHI), and with an improvement in the average $\mathrm{SpO} 2$ as well as in the value of the minimum $\mathrm{SpO} 2$ detected during sleep in children with a history of Apparent Life-Threatening Events (ALTEs) [18].

The effects of pacifiers on the variations in peripheral oxygen saturation during wake time are unclear. One study [19] compared different sleeping positions in relation to changes in cardio-respiratory parameters. The positions studied were prone, supine, and lateral. While the prone position seems to be ideal for premature infants with mechanical ventilation, the same cannot be said for spontaneously breathing premature infants. In addition, due to the association between the prone sleeping position and SIDS [13], all hospitalized infants placed in the prone position must be continuously monitored in terms of SpO2 levels. Lister et al. (2012) showed that infants placed in the prone or the side position were no more likely to experience an extreme cardiorespiratory event, compared with infants placed in the supine position [20]. This study concluded that, other than decreasing extreme cardiorespiratory events, exactly how the supine sleeping position decreases the risk of SIDS is unclear.

The difference between the supine position and the same position inclined at $30^{\circ}$ has not yet been analyzed in healthy children. Deye et al., (2012) studied the influence of posture on breathing effort in patients with difficult weaning [21]. They hypothesized that posture could modulate the breathing effort in difficult-to-wean patients. Their prospective, crossover, physiological study was performed in 24 intubated patients breathing with pressure support who had already failed a spontaneous breathing trial or extubation episode. The results highlighted that the $45^{\circ}$ position helps to unload the respiratory muscles, moderately reduces PEEP(i), and is often considered as comfortable. The semiseated position may help the weaning process in ventilator-dependent patients. The results of another study on the changes in body positions of adult patients receiving mechanical ventilation in the intensive care unit showed that the sitting position (with a thorax angulation of $>30^{\circ}$ from the horizontal plane) was associated with an improvement in functional residual capacity (FRC), oxygenation, and reduced breathing effort [22].

To the best of our knowledge, there are no other studies on $\mathrm{SpO} 2$ variations in relation to these two positions; however, according to the Italian Guidelines for Apparent LifeThreatening Events (ALTE) [23], gastroesophageal reflux may be related to episodes of apnea. In these cases, the supine position at $30^{\circ}$ inclination, dubbed the "anti-reflux position", is advised in order to reduce the frequency of these episodes. Gastroesophageal reflux is considered physiological in the first year of life (unless severe or recurrent).

The purpose of our study was to compare SpO2 variations, registered with an oximeter, in relation to pacifier use and different positions (supine and supine inclined at $30^{\circ}$ ).

\section{Materials and Methods}

The selected sample comprised infants between 0 and 3 years of age, weighing over $1.800 \mathrm{~g}$, and hospitalized in the Pediatric Unit in Varese (Italy), for various reasons (a urinary tract infection, an upper airway infection, a fever $>38{ }^{\circ} \mathrm{C}$ with or without seizures, chickenpox, suspected ALTE, bronchiolitis). Infants with cardio-respiratory anomalies 
were excluded. All the patients were born at term. The patients' parents all signed an informed consent, and no economic incentive was given in exchange for participation. The study was authorized by the provincial Ethics Committee of Varese (Italy).

Each patient was monitored in terms of peripheral oxygen saturation $(\mathrm{SpO} 2)$ with a Getemed Vitaguard 3100 oximeter. For patients aged under 12 months, observation time lasted $40 \mathrm{~min}$, of which $20 \mathrm{~min}$ were spent in the supine position (10 min with a pacifier and $10 \mathrm{~min}$ without), and $20 \mathrm{~min}$ at 30 degrees inclination (10 min with a pacifier and 10 min without).

For patients aged over 12 months, the observation time lasted $40 \mathrm{~min}$, of which $20 \mathrm{~min}$ were spent in the supine position (10 min with a pacifier and $10 \mathrm{~min}$ without), and $20 \mathrm{~min}$ were spent in the sitting position (10 min with a pacifier and $10 \mathrm{~min}$ without).

For each patient, we recorded the maximum and minimum $\mathrm{SpO} 2$, and calculated the average saturation rate in the different registration times. We then compared the data to check for $\mathrm{SpO} 2$ variations in relation to the presence or absence of the pacifier and the different positions.

To limit the confounding effect related to nychthemeral influences, half the sample was randomized for monitoring with a pacifier, while the remaining half began without a pacifier. The patients used their own personal pacifiers. We recorded the specific models (orthodontic, cherry-shaped, teardrop-shaped).

The data were statistically analyzed with non-parametric tests for paired data, with a significance level of alpha $=0.05$ (two tailed test).

\section{Results}

We tested 54 infants, aged between 0 and 3 years, weighing over $1.800 \mathrm{~g}$, of which 21 were female and 33 were male. The average age of the participants was 5.7 months. The study sample was limited to a population between 0 and 3 years old in accordance with the Italian ministerial guidelines, which suggest the use of the pacifier in this age range [24].

The average $\mathrm{SpO} 2$ reading in the supine position at $0^{\circ}$ inclination was $96.3( \pm 2.1)$ and $97.4 \%( \pm 2.0)$ without and with a pacifier, respectively. In the supine position at $30^{\circ}$, the average $\mathrm{SpO} 2$ reading was $96.3( \pm 2.2)$ and $97.3 \%( \pm 2.1)$ without and with a pacifier, respectively. In the trials with a pacifier in the supine position at $0^{\circ}$, an improvement in the average $\mathrm{SpO} 2$ of +1.1 percentage points was found for all the patients. In the sitting position $/$ at $30^{\circ}$ inclination, the average $\mathrm{SpO} 2$ improved by +1.0 percentage points compared to the trials conducted without a pacifier, and this difference was statistically significant $(p$ value $<0.05$ ) (Figure 1). A significant improvement of +1.1 percentage points was recorded in the average $\mathrm{SpO} 2$ with a pacifier at $0^{\circ}$ inclination compared to no pacifier at $30^{\circ}$ inclination/in sitting position. The average $\mathrm{SpO} 2$ improved by +1.0 percentage points with a pacifier at $30^{\circ}$ compared to no pacifier at $0^{\circ}$.

Lastly, we analyzed the variations in $\mathrm{SpO} 2$ in relation to the different positions. In the trials with a pacifier, the $\mathrm{SpO} 2$ levels were no better in the sitting position/in the supine position at $30^{\circ}$ than in the $0^{\circ}$ position. Without a pacifier, the average SpO2 level in the sitting position $/$ at $30^{\circ}$ (SpO2 $96.3 \%$ ) was the same as the $0^{\circ}$ position (SpO2 96.3\%). All the infants seemed comfortable during the $\mathrm{SpO} 2$ reading. 


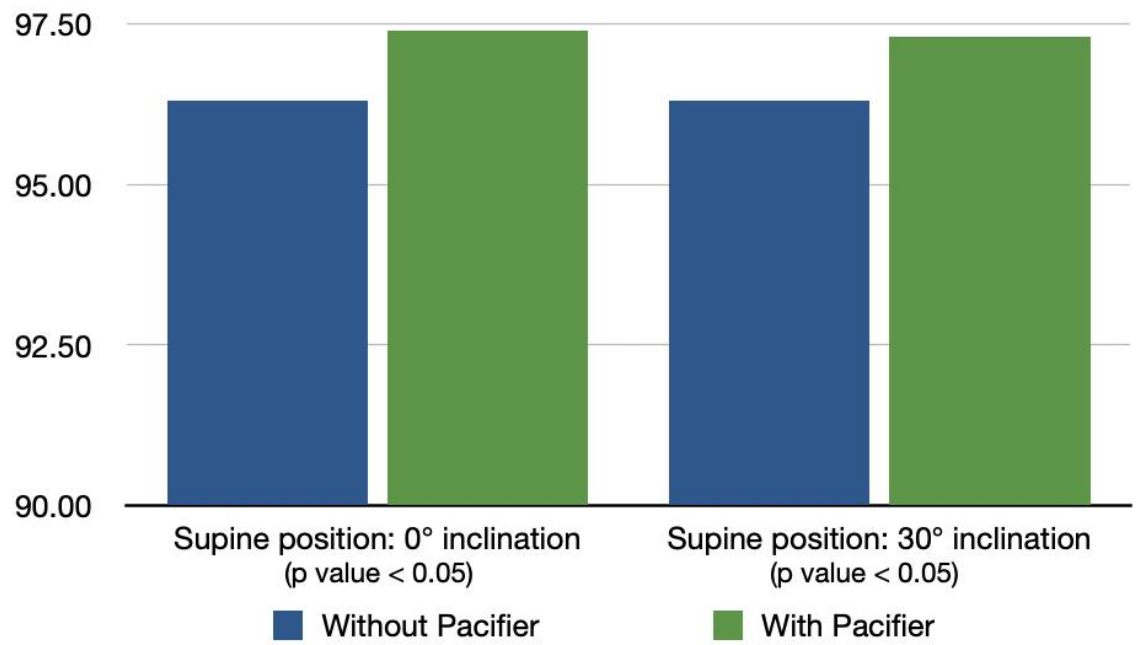

Figure 1. Main results.

\section{Discussion}

Our results highlight that pacifier use improves $\mathrm{SpO} 2$ levels in infants during wake time. They also show that the supine position at $30^{\circ}$ inclination does not improve $\mathrm{SpO} 2$ levels during wake time. Pacifier use, thus, seems to have a positive effect on peripheral capillary oxygen saturation. No problems or irritation of the oral mucosa related to the pacifier use were observed by the parents or medical staff during the tests.

The results are line with the literature, although there are few articles on this subject. Analyzing arterial oxygen saturation, Cozzi (2002) demonstrated that pacifier use during sleep improved the maintenance of patent airways and an adequate oral airflow in healthy infants born at term, especially for patients suffering from nasal occlusion [17]. This result was correlated with the fact that a pacifier pushes the tongue forwards and upwards, favoring the airflow around the pacifier, and between the tongue and the palate. Tonkin (2007) hypothesized that the association between pacifier use and a reduced risk of SIDS could be related to the forward movement of the maxilla and, consequently, of the tongue, which helps to maintain patent upper airways. [16]

We thus measured the distance between the ear and the most prominent point of the chin in pre-term infants before and after using a pacifier for around $15 \mathrm{~min}$. A small but significant advancement of the maxilla was observed, which was maintained after the pacifier had been removed. This confirmed the positive effect of the pacifier on the upper airways. Data from lateral neck radiographs also suggest an association between ALTE and narrowing of the upper airways [25]). Levrini and Nosetti conducted a study at the Pediatric Unit of the Hospital Filippo del Ponte (Varese, Italy) between 2017 and 2018. They found that pacifier use in infants aged between 0 and 2 years, who were hospitalized after an ALTE/BRUE episode, significantly reduced the incidence of apnea and hypopnea (AHI), that is, the absolute number of apneas/hypopneas per hour, measured using a complete polysomnography during afternoon rest [18].

With regard to the position, our results showed no improvement in SpO2 levels in the supine position at $30^{\circ} /$ in sitting position compared to the those measured in the supine position at $0^{\circ}$.

This study confirms that the use of pacifiers led to an improvement in the average $\mathrm{SpO} 2$ in both positions tested. The results also suggest that the improved $\mathrm{SpO} 2$ levels are directly correlated to pacifier use and are not impacted by the different positions tested. 
Pacifiers thus represent an excellent tool not only in preventing SIDS, in calming the baby, in reducing the perception of pain during painful procedures, and in reducing finger sucking habits, but also in improving breathing both during sleep and while awake.

Pacifiers should thus be used after the first month of life, once breastfeeding has been consolidated, and no later than 36 months of age to prevent misalignment of the dental arch.

\section{Recommendations for the Correct Use of the Pacifier}

The use of pacifiers has always been a topic of interest for both parents and the scientific world. To date, with a few exceptions, all aspects of the correct use of the pacifier have been fully clarified. Simple and practical clinical recommendations can thus be given [26].

Some key recommendations are as follows: the use of a pacifier reassures the infant and the family. However, pacifiers should not be used as a substitute for the parent-child relationship and parents should only resort to it when the newborn would clearly benefit from it, and not when the infant's desire to communicate is evident. In fact, a pacifier should not be used to stop a newborn from crying, which in most cases is an expression of a need that should not be ignored $[7,27,28]$.

To prevent malocclusion, it is advisable to use a pacifier for 24 months and stop before 36 months. Its use also stimulates the physiological tone of the perioral musculature and indirectly, the correct growth of the maxillary bones $[10,29,30]$.

The shape of the pacifier is important and should be adapted to the anatomy of the oral cavity. It should stimulate oral functions such as swallowing, lip competence, and breathing $[4,31,32]$; breathing is just one of the functional benefits that derive from the use of a pacifier [15-18].

It is important that pacifiers be used sparingly until breastfeeding has started; if there is a decrease in the availability of breast milk, the use of pacifiers should be reduced to facilitate physiological breastfeeding [11,33,34]. In order to reduce the risk of SIDS, a pacifier should be used during the first year of life for both day and night sleep $[13,35,36]$. In order to prevent pain and lesions, it is very important that pacifiers should never be used with sweeteners [37-39].

Finally, the risk of acute otitis media is higher in those subjects who use a pacifier very frequently, and thus it is not recommended in young children with recurrent otitis $[12,30,40]$.

Taking into account the baby's oral health and growth and its relationship with the use of a pacifier, appropriate oral hygiene in growing infants [41], particularly in those with a disability and special needs, is fundamental for the overall health of their dental and skeletal growth [42]. In addition, it is important to evaluate the periodontal biotype of the patients and the stability of the pacifiers' use [42-44].

\section{Conclusions}

In the light of these observations, when prescribing the use of an anatomical/functional pacifier within the first three years of life, an orthodontist and a pediatric dentist could add the evidence that it triggers the ability to improve, even if slightly, the complex respiratory system to its beneficial effects.

Author Contributions: Conceptualization, L.L. and L.N.; methodology, L.L.; software, L.L.; validation, L.L., F.R., and L.N.; formal analysis, L.L.; investigation, L.L., F.R., V.M., L.A., and L.N.; resources, L.L.; data curation, L.L.; writing—original draft preparation, L.L. and F.R.; writing—review and editing, L.L., V.M., and L.A.; visualization, L.L., V.M., and L.A.; supervision, L.N.; project administration, L.L. All authors have read and agreed to the published version of the manuscript.

Funding: This research received no external funding. 
Institutional Review Board Statement: The study was conducted according to the guidelines of the Declaration of Helsinki, and approved by the Ethics Committee of ASST Sette Laghi, Ospedale di Circolo Fondazione Macchi, Varese, Italy (2016-187, 2017-110: 5 September 2017).

Informed Consent Statement: Informed consent was obtained from all subjects involved in the study.

Data Availability Statement: Data are available on demand.

Conflicts of Interest: The authors declare no conflict of interest.

\section{References}

1. Moimaz, S.A.; Garbin, A.J.; Lima, A.M.; Lolli, L.F.; Saliba, O.; Garbin, C.A. Longitudinal study of habits leading to malocclusion development in childhood. BMC Oral Health 2014, 4, 14-96. [CrossRef] [PubMed]

2. Costa, C.T.D.; Shqair, A.Q.; Azevedo, M.S.; Goettems, M.L.; Bonow, M.L.M.; Romano, A.R. Pacifier use modifies the association between breastfeeding and malocclusion: A cross-sectional study. Braz. Oral Res. 2018, 11, 32. [CrossRef] [PubMed]

3. Doğramacı, E.J.; Rossi-Fedele, G. Establishing the association between nonnutritive sucking behavior and malocclusions: A systematic review and meta-analysis. J. Am. Dent. Assoc. 2016, 147, 926-934.e6. [CrossRef]

4. Schmid, K.M.; Kugler, R.; Nalabothu, P.; Bosch, C.; Verna, C. The effect of pacifier sucking on orofacial structures: A systematic literature review. Prog. Orthod. 2018, 19, 8. [CrossRef]

5. Hanzer, M.; Zotter, H.; Sauseng, W.; Pichler, G.; Muller, W.; Kerbl, R. Non-Nutritive Sucking Habits in Sleeping Infants. Neonatology 2010, 97, 61-66. [CrossRef] [PubMed]

6. Stüdeli, T. Ergonomic recommendations for the Design of Pacifiers. In Proceedings of the 5th International Conference on Applied Human Factors and Ergonomics AHFE, Kraków, Poland, 19-23 July 2014.

7. Fein, J.A.; Zempsky, W.T.; Cravero, J.P. Relief of pain and anxiety in pediatric patients in emergency medical systems. Pediatrics 2012, 130, 1391-1405. [CrossRef]

8. Foster, J.P.; Psaila, K.; Patterson, T. Non-nutritive sucking for increasing physiologic stability and nutrition in preterm infants. Cochrane Database Syst. Rev. 2016, 4, 10. [CrossRef]

9. Larsson, E.F.; Dahlin, K.G. The prevalence and the etiology of the initial dummy- and finger-sucking habit. Am. J. Orthod. 1985, 87, 432-4355. [CrossRef]

10. Góis, E.G.; Ribeiro-Júnior, H.C.; Vale, M.P.; Paiva, S.M.; Serra-Negra, J.M.; Ramos-Jorge, M.L.; Pordeus, I.A. Influence of nonnutritive sucking habits, breathing pattern and adenoid size on the development of malocclusion. Angle Orthod. 2008, 78, 647-654. [CrossRef]

11. Howard, C.R.; Howard, F.M.; Lanphear, B.; Eberly, S.; de Blieck, E.A.; Oakes, D.; Lawrence, R.A. Randomized clinical trial of pacifier use and bottle-feeding or cupfeeding and their effect on breastfeeding. Pediatrics 2003, 111, 511-518. [CrossRef]

12. Rovers, M.M.; Numans, M.E.; Langenbach, E.; Langenbach, E.; Grobbee, D.E.; Verheij, T.J.; Schilder, A.G. Is pacifier use a risk factor for acute otitis media? A dynamic cohort study. Fam. Pract. 2008, 25, 233-236. [CrossRef]

13. Moon, R.Y.; Task Force on Sudden Infant Death Syndrone. SIDS and Other Sleep-Related Infant Deaths Evidence Base for 2016 Updated Recommendations for a Safe Infant Sleeping Environment. Pediatrics 2016, 138, e20162940. [CrossRef] [PubMed]

14. Franco, P.; Scaillet, S.; Wermenbol, V.; Valente, F.; Groswasser, J.; Kahn, A. The influence of a pacifier on infants' arousals from sleep. J. Pediatr. 2000, 136, 775-779.

15. Li, D.K.; Willinger, M.; Petitti, D.B. Use of a dummy (pacifier) during sleep. BMJ 2006, 7, 18-22. [CrossRef]

16. Tonkin, S.L.; Lui, D.; McIntosh, C.G.; Rowley, S.; Knight, D.B.; Gunn, A.J. Effect of pacifier use on mandibular position in preterm infants. Acta Paediatr. 2007, 96, 1433-1436. [CrossRef] [PubMed]

17. Cozzi, F.; Morini, F.; Tozzi, C.; Bonci, E.; Cozzi, D.A. Effect of pacifier use on oral breathing in healthy newborn infants. Pediatr. Pulmonol. 2002, 33, 368-373. [CrossRef]

18. Levrini, L.; Nosetti, L.M.; Riggi, L.; Montericcio, L.; Agosti, M. Sleep Apnea throughout the First Two Years of Life: Assessment of the Effect of Pacifiers in Patients with ALTE. Open Dent. J. 2019, 13, 48-52. [CrossRef]

19. Ballout, R.A.; Foster, J.P.; Kahale, L.A.; Badr, L. Body positioning for spontaneously breathing preterm infants with apnoea. Cochrane Database Syst. Rev. 2017. [CrossRef]

20. Lister, G.; Rybin, D.V.; Colton, T. Relationship between sleep position and risk of extreme cardiorespiratory events. J. Pediatr. 2012, 161, 22-25. [CrossRef] [PubMed]

21. Deye, N.; Lellouche, F.; Maggiore, S.M.; Taille, S.; Demoule, A.; L'Her, A.; Galia, F.; Harf, A.; Mancebo, J.; Brochard, L. The semi-seated position slightly reduces the effort to breathe during difficult weaning. Intensive Care Med. 2012, 39, 85-92. [CrossRef]

22. Mezidi, M.; Guérin, C. Effects of patient positioning on respiratory mechanics in mechanically ventilated ICU patients. Ann. Transl. Med. 2018, 6, 384. [CrossRef]

23. Piumelli, R.; Davanzo, R.; Nassi, N. Apparent Life-Threatening Events (ALTE): Italian guidelines. Ital. J. Pediatr. 2017, $12,111$. [CrossRef] [PubMed]

24. Linee Guida Nazionali per la Promozione Della Salute Orale e la Prevenzione Delle Patologie Orali in Eta' Evolutiva. Available online: https://www.salute.gov.it/imgs/C_17_pubblicazioni_867_allegato.pdf (accessed on 1 December 2020). 
25. Gunn, T.R.; Tonkin, S.L.; Hadden, W.; Davis, S.L.; Gunn, A.J. Neonatal micrognathia is associated with small upper airways on radiographic measurement. Acta Paediatr. 2000, 89, 82-87. [CrossRef] [PubMed]

26. Cornelius, A.N.; D'Auria, J.P.; Wise, L.M. Pacifier use: A systematic review of selected parenting web sites. J. Pediatr. Health Care 2008, 22, 159-165. [CrossRef] [PubMed]

27. Lewkowski, M.D.; Barr, R.G.; Sherrard, A.; Lessard, J.; Harris, A.R.; Young, S.N. Effects of chewing gum on responses to routine painful procedures in children. Physiol. Behav. 2003, 79, 257-265. [CrossRef]

28. Cinar, D.N. The advantages and disadvantages of pacifier use. Contemp. Nurse 2004, 17, 109-112. [CrossRef]

29. Poyak, J. Effects of pacifiers on early oral development. Int. J. Orthod. 2006, 17, 13-16.

30. Nelson, A.M. A comprehensive review of evidence and current recommendations related to pacifier usage. J. Pediatr. Nurs. 2012, 27, 690-699. [CrossRef]

31. Zimmerman, E.; Forlano, J.; Gouldstone, A. Not All Pacifiers Are Created Equal: A Mechanical Examination of Pacifiers and Their Influence on Suck Patterning. Am. J. Speech Lang Pathol. 2017, 26, 1202-1212. [CrossRef]

32. Levrini, L.; Merlo, P.; Paracchini, L. Different geometric patterns of pacifiers compared on the basis of finite element analysis. Eur. J. Paediatr. Dent. 2007, 8, 173-178.

33. Jaafar, S.H.; Ho, J.J.; Jahanfar, S.; Angolkar, M. Effect of restricted pacifier use in breastfeeding term infants for increasing duration of breastfeeding. Cochrane Database Syst. Rev. 2016. [CrossRef]

34. Buccini, G.D.S.; Pérez-Escamilla, R.; Paulino, L.M.; Araújo, C.L.; Venancio, S.I. Pacifier use and interruption of exclusive breastfeeding: Systematic review and meta-analysis. Matern. Child Nutr. 2017, 3, e12384. [CrossRef]

35. Sexton, S.; Natale, R. Risks and benefits of pacifiers. Am. Fam. Physician 2009, 79, 681-685.

36. Adams, S.M.; Ward, C.E.; Garcia, K.L. Sudden infant death syndrome. Am. Fam. Physician 2015, 91, 778-783.

37. Paglia, L.; Scaglioni, S.; Torchia, V. Familial and dietary risk factors in Early Childhood Caries. Eur. J. Paediatr. Dent. 2016, 17, 93-99.

38. Goodwin, M.; Patel, D.K.; Vyas, A. Sugar before bed: A simple dietary risk factor for caries experience. Community Dent. Health 2017, 34, 8-13.

39. Baghlaf, K.; Muirhead, V.; Moynihan, P.; Weston-Price, S.; Pine, C. Free Sugars Consumption around Bedtime and Dental Caries in Children: A Systematic Review. JDR Clin. Trans. Res. 2018, 3, 118-129. [CrossRef] [PubMed]

40. Marchisio, P.; Bortone, B.; Ciarcià, M. Updated Guidelines for the Management of Acute Otitis Media in Children by the Italian Society of Pediatrics: Prevention. Pediatr. Infect Dis. J. 2019, 38 (Suppl. S12), S22-S36. [CrossRef]

41. Roncati, M.; Polizzi, E.; Cingano, L.; Gherlone, E.F.; Lucchese, A. An oral health aid for disabled patients. Dent. Cadmos 2013, 81, 447-452. [CrossRef]

42. Gandini, P.; Schiavi, A.; Manuelli, M.; Camassa, D. Epidemiological survey of caries occurrence in school age children. Mondo Ortod. 1989, 14, 63-72.

43. Lucchese, A.; Carinci, F.; Brunelli, G.; Monguzzi, R. Everstick®and Ribbond®fiber reinforced composites: Scanning Electron Microscope (SEM) comparative analysis. Eur. J. Inflamm. 2011, 9, 73-79.

44. Matarese, G.; Isola, G.; Ramaglia, L.; Dalessandri, D.; Lucchese, A.; Alibrandi, A.; Fabiano, F.; Cordasco, G. Periodontal biotype: Characteristic, prevalence and dimensions related to dental malocclusion. Minerva Stomatol. 2016, 65, 231-238. 